Original article

\title{
Teachers' knowledge about epilepsy
}

\author{
Hamidreza Reyace ${ }^{1}$, Sima Kaheni ${ }^{2}{ }^{* *}$, Gholamreza Sharifzadeh ${ }^{3}$
}

(Received: 14 Mar 2013; Accepted 27 Jul 2013)

\begin{abstract}
Background and Purpose: Epilepsy is a disease frequently seen among school children. Teachers may be distressed by children having seizures as they do not receive specific training about this condition during their education. Moreover, teachers can feel overwhelmed if they do not know how to handle the situation. After cerebral apoplexy, epilepsy is the second most common central nervous system disorder and the death rate is two to three times higher in children who have epilepsy than in those who do not. This research was conducted to determine teacher's knowledge level about epilepsy.

Methods: In this cross-sectional study, elementary schools in 10 urban areas of Birjand City, Iran, were included and a cluster of 20 schools was selected. In order to evaluate the teachers' knowledge of epilepsy, we used a survey consisting of five demographic information questions, five questions concerning familiarity with the disease, and 22 questions about their knowledge of the condition. The survey was prepared by the researcher and its content validity was confirmed by 10 experts, in addition test-retest validity was verified. Then the responses were gathered and analyzed using SPSS software.

Results: According to this research findings, the average level of teachers' knowledge was 13.9 out of 22 . Overall, $70.9 \%$ of the teachers obtained an average level of $17.7 \%$ as a good level and $11.4 \%$ as a weak level of knowledge.

Conclusion: This research showed that the majority of teachers had an average level of understanding of epilepsy. Therefore, according to the above results, teachers would benefit from having further education about this condition during their service as this would assist them to develop their level of knowledge and help them to support such children more effectively.
\end{abstract}

Keywords: Epilepsy, Teacher's knowledge, School-age children

\section{Introduction}

Epilepsy is the most common neurological problem in childhood. Not only the disease itself, but also the drugs used to treat this condition may lead to certain cognitive, psychosocial, and behavioral problems (1). Epilepsy is the second most important factor in central nervous system (CNS) illnesses, following cardio vascular accidents (CVA). Approximately one to five percent of people in the world suffer from this illness (2). In Iran, in every 1000 school aged children, there are 4.2 youngsters suffering from epilepsy. Furthermore, $65 \%$ of those affected by epilepsy are teenagers and children (3). It has been well established that children with epilepsy have a higher incidence of school underachievement due to a range of factors including the medications that are used to treat their seizures, psychosocial difficulties and behavioral problems, not to mention the social stigma and discrimination experienced by people with epilepsy (4). Epilepsy is a prevalent illness and it occurs mainly in the teenage years, ignoring this

${ }^{1}$ Department of Neurology, School of Medicine, Birjand University of Medical Sciences, Birjand, Iran.

${ }^{2, *}$ Corresponding author:Department of Pediateric Nursing/Member of faculty, Nasibeh Nursing and Midwifery School, Mazandaran University of Medical Sciences, Sari/ Iran Email:kaheni2012@yahoo.com

${ }^{3}$ Department of Epidemiology, School of Medicine, Birjand University of Medical Sciences, Birjand, Iran. 
fact may have a negative effect on the education and social behavior of the person and also on the economic situation of the county. Unfortunately, it has frequently been shown that children with epilepsy, for a variety of reasons, are at increased risk of a number of education-related problems that negatively affect their current quality of life and place them at increased risk of psychosocial problems later in adolescence and adulthood. Specifically, children with epilepsy are at increased risk of educational underachievement, learning disabilities, mental health problems, social isolation, and poor self-esteem (5).

For a person not familiar with absence epilepsy (petit mal seizures) in children, this is easily confused with a typical daze and the teachers who do not know about this kind of convulsion may develop wrong attitude towards epileptic children. On the other hand, since these convulsions happen frequently, students may miss a lot of educational information and the teacher may be unaware of the reasons why a student's marks have decreased. Movement convulsions such as generalized epilepsy (grand mal seizures) are more easily recognized but if the teacher does not have sufficient information about this condition, it could result in serious problems in classroom to control the situation which would also be harmful for the epileptic child (6). Teachers' knowledge about and attitudes towards epilepsy can have a direct impact on the students with epilepsy, in terms of their school performance, social skill development, and post-school success in the areas of employment, social skills and social network development (7). Since some teachers lack awareness of how to deal with convulsions, they may be afraid to do anything. In addition, because teachers may not be able to help the other students understand this illness, they may inadvertently cause communication problems between the epileptic child and his/her classmates. If the teacher is not aware of this problem, they could mistakenly interpret the convulsions as a behavior disorder which would definitely have adverse consequences for the epileptic child (8). Teachers must increase their scientific knowledge and skills about this condition in order to give these students a greater educational chance and to help them to care for this illness correctly, because not controlling the epilepsy will have a negative effect on the individual student's learning ability and educational achievement as well as contributing to the future economic and social problems (9). According to a study conducted on epilepsy awareness of the teachers in Nigeria, $10 \%$ had a good understanding, $45 \%$ got an average score and $43 \%$ of the them had a poor level of knowledge (10). According to a study performed on knowledge about and attitudes toward epilepsy among school teachers and counselors in Jordan, the results showed an average level of knowledge about the students with epilepsy. Findings indicated that more information and awareness should be provided to teachers and counselors within the Jordanian schooling systems (11). According to a study done on knowledge about and attitudes towards epilepsy among primary, secondary and tertiary level teachers, it was found that teachers do not usually receive any formal instruction about epilepsy during their training. Almost all of the teachers had heard about epilepsy, though, they could not recognize the condition among their students (12). Since a teacher's knowledge about epilepsy has a direct effect on a child's educational progress and social skills, as well as on their social communication and future success, it is vital that medical and support personnel do their best to provide adequate information about the treatment of this malady to people in society. In order to achieve this goal, we conducted a survey on teachers' knowledge about epilepsy. This study was carried out in the elementary schools in Birjand City, Iran.

\section{Materials and Methods}

This cross-sectional study was conducted in 2010, with the teachers selected using a multi-phased cluster sampling method. According to its geographical zones, Birjand City has ten health centers and it is divided into ten areas. One boys school and one girls elementary school were chosen from the schools located in each area and ultimately, 20 schools were selected. The sampling method for the teachers 
was by census and all the teachers in the selected schools were chosen. Questionnaires to determine the knowledge level of the teachers have been available to them \& were carried out by the trained students. The questionnaires included 32 questions in total: five questions related to demographic information, five questions about familiarity with epilepsy and 22 questions were on knowledge about epilepsy. Responses in the questionnaire were based on Likert scale from 1-6 (1= do not know, $2=$ very weak, $3=$ weak, $4=$ moderate, $5=$ good, $6=$ very good), and the total scores were calculated. The minimum score was 22 and the maximum was 132. A score of 22-59 was considered as weak knowledge, 59-95 as average knowledge, and a score higher than 95 indicated good knowledge. The content validity of the questionnaire was evaluated. The questionnaire was submitted to ten specialists for revision and correction. To assess the questionnaire's reliability, test-retest $(r=0.75)$ was used. After collecting the responses, data was analyzed using 16 SPSS software, along with Fisher's exact test and Chi-squared test at significance level $\alpha=0.05$.

\section{Results}

Among 158 elementary school teachers, 70.9\% (112 teachers) scored in the average range, 17.7\% (28 teachers) obtained a good score and $11.4 \%$ (18 teachers) had a weak level of knowledge. The average knowledge score of teacher was 22 out of a range of 13-89. The average age of the subjects was 41.4 years and the average teaching experience was 6.5 years. Most of our research participants were female ( 99 subjects $=62.7 \%$ ), university educates with a BSc or higher degree and married (148 subjects $=93.7 \%)$. Moreover, $77.8 \%$ of the teachers (123 subjects) did not have sufficient experience to teach epileptic students while $82.9 \%$ of the teachers (131 subjects) did not have any knowledge to assist an epileptic child including first aid. According to the statistical analysis, there was no significant relationship between the knowledge scores of the teachers and their gender, teaching experience of an epileptic child, passing first aid course or experience in helping an epileptic child. However, there was a significant relationship between the teachers' level of knowledge and hearing information about epilepsy. There was no significant relationship between the average knowledge score and gender, education level and teaching experience with an epileptic child, including experience of helping an epileptic child (Table 1).

\section{Discussion}

The present study was carried out in order to evaluate the level of elementary school teachers' knowledge of epilepsy and the results indicated that the level of knowledge in 2010 got an average score of 22. In a similar study undertaken by Alikor in 2005 about the knowledge of elementary school teachers towards epilepsy in Nigeria, 10 percent got a good score, 45 percent got average and 43 percent gained a weak score that are similar to the results of the present study(9). In Emily's study (1999) consisting of a survey on teachers' knowledge about epilepsy, it was revealed that the average score of teachers' knowledge was 54 (minimum 11, maximum 66; the difference may be due to less training classes for teachers than in Iranian teachers (4). In Gretchen's study (2006) knowledge summary scores ranged from 2 to 9 (mean $=5.2$, median $=7.0$, mode $7.0 \& \mathrm{SD}=3.0$ ). The majority of the teachers $(>70 \%)$ recognized epilepsy as a brain-related disorder but supernatural beliefs such as witchcraft $(16.8 \%)$ and spirit possession $(20.0 \%)$ were evident, even in this educated population (13). In Ghaydaa's study (2010), $100 \%$ of widows, $51.2 \%$ of female teachers had correct information about epilepsy (6).

According to the present study results, there was no significant relationship between the teachers' knowledge and their gender, age and education levels, although there was a meaningful relationship determined between the teachers' knowledge level and what they had heard about epilepsy $(\rho=0 / 006)$. In Emily's study, there was also no significant relationship between the teachers' knowledge and their age, gender or education level. In addition, in Ghaydaa's study, no meaningful relationship was found between 
the teachers' knowledge and their gender $(10,6)$ which was similar to our study. In the present study, significant relationship was determined between the rate of knowledge and teachers' experience. In the studies by Malachy and Emily there was a meaningful relationship between the level of knowledge and the teachers' experience $(10,14)$; hence they are not the same. The differences observed in the present study could be the result of higher level of communication between the teachers and their epileptic students. Based on the present study results, $46.2 \%$ of the teachers believed that epilepsy was a mental disorder. In the studies by Lee (2010) and Kaleyias (2000) in Greece, $69.4 \%$ and $85 \%$, respectively, believed that epilepsy was a mental disorder. Ghare Gazli conducted a survey on people's knowledge and attitude towards epilepsy in Tehran, people considered a mental disorder as the reason behind epilepsy $(15,16 \& 17)$.

Table 1. Relationship between Teachers' knowledge about Epilepsy \& some Related Factors

\begin{tabular}{|c|c|c|c|c|}
\hline Teachers knowledge & Weak & Medium & good & $\begin{array}{c}\text { Statistical } \\
\text { tests }\end{array}$ \\
\hline \multicolumn{5}{|l|}{ Personal Information } \\
\hline \multicolumn{5}{|l|}{ Sex } \\
\hline Male & $9(15.3)$ & $41(69.5)$ & $9(15.3)$ & $\rho=0.45$ \\
\hline Female & $9(9.1)$ & 71(71.7) & $19(19.2)$ & \\
\hline \multicolumn{5}{|l|}{ Hearing about Epilepsy } \\
\hline Yes & $13(9)$ & $106(73.1)$ & $26(17.9)$ & $\rho=0.01$ \\
\hline No & $5(38.5)$ & $6(46.2)$ & $2(15.2)$ & \\
\hline \multicolumn{5}{|c|}{$\begin{array}{l}\text { Teaching experience to the } \\
\text { epileptic child }\end{array}$} \\
\hline Has & $4(11.4)$ & $22(62.9)$ & $9(25.7)$ & $\rho=0.36$ \\
\hline Dosen't have & $14(11.4)$ & $90(70.3)$ & $19(15.4)$ & \\
\hline \multicolumn{5}{|l|}{$\begin{array}{l}\text { Experience first aid } \\
\text { courses }\end{array}$} \\
\hline Yes & $1(2.7)$ & $269(70.3)$ & $10(27)$ & $\rho=0.06$ \\
\hline No & $17(14)$ & $86(71.1)$ & $18(14.9)$ & \\
\hline \multicolumn{5}{|l|}{$\begin{array}{l}\text { Experience in helping the } \\
\text { epileptic child }\end{array}$} \\
\hline Yes & $2(7.4)$ & $17(63)$ & $8(29.6)$ & $\rho=0.19$ \\
\hline No & $16(12.2)$ & $95(72.5)$ & $20(15.3)$ & \\
\hline \multicolumn{5}{|l|}{ Education level } \\
\hline Diploma & $4(28.6)$ & $9(64.3)$ & $1(7.1)$ & $\rho=0.14$ \\
\hline Above diploma & $8(12.7)$ & $41(65.1)$ & $14(22.2)$ & \\
\hline B.Sc or higher & $6(7.4)$ & $62(76.5)$ & $13(16)$ & \\
\hline
\end{tabular}

JNMS 2014; $1(1)$

\section{Conclusion}

The present study was carried out in order to evaluate the level of elementary school teachers' knowledge of epilepsy and the results indicated that the level of knowledge in 2010 got an average score of 22. In a similar study undertaken by Alikor in 2005 about the knowledge of elementary school teachers towards epilepsy in Nigeria, 10 percent got a good score, 45 percent got average and 43 percent gained a weak score that are similar to the results of the present study (9). In Emily's study (1999) consisting of a survey on teachers' knowledge about epilepsy, it was revealed that the average score of teachers' knowledge was 54 (minimum 11, maximum 66; the difference may be due to less training classes for teachers than in Iranian teachers (4). In Gretchen's study (2006) knowledge summary scores ranged from 2 to 9 (mean $=5.2$, median= 7.0 , mode $7.0 \& \mathrm{SD}=3.0$ ). The majority of the teachers $(>70 \%)$ recognized epilepsy as a brain-related disorder but supernatural beliefs such as witcheraft (16.8\%) and spirit possession $(20.0 \%)$ were evident, even in this educated population (13). In Ghaydaa's study (2010), $100 \%$ of widows, $51.2 \%$ of female teachers had correct information about epilepsy (6).

According to the present study results, there was no significant relationship between the teachers' knowledge and their gender, age and education levels, although there was a meaningful relationship determined between the teachers' knowledge level and what they had heard about epilepsy $(\rho=0 / 006)$. In Emily's study, there was also no significant relationship between the teachers' knowledge and their age, gender or education level. In addition, in Ghaydaa's study, no meaningful relationship was found between the teachers' knowledge and their gender $(10,6)$ which was similar to our study. In the present study, significant relationship was determined between the rate of knowledge and teachers' experience. In the studies by Malachy and Emily there was a meaningful relationship between the level of knowledge and the teachers' experience $(10,14)$; hence they are not the same. The differences observed in the present study 
could be the result of higher level of communication between the teachers and their epileptic students. Based on the present study results, $46.2 \%$ of the teachers believed that epilepsy was a mental disorder. In the studies by Lee (2010) and Kaleyias (2000) in Greece, $69.4 \%$ and $85 \%$, respectively, believed that epilepsy was a mental disorder. Ghare Gazli conducted a survey on people's knowledge and attitude towards epilepsy in Tehran, people considered a mental disorder as the reason behind epilepsy $(15,16 \& 17)$.

In the present study, $16.5 \%$ of the teachers believed that epileptic children do not have natural intelligence, and in a similar study (2006) concerning teacher's knowledge of epilepsy in Holland, $31.7 \%$ of the teachers believed that epileptic children's IQs were lower than the average level (18). However, in Ghorehgozli's study, $94 \%$ of the people surveyed also believed that epileptic children could continue their studies (17). In Bishop's study, 27.8\% of the teachers have administered first aid to epileptic children while in our study, $17.1 \%$ of the teachers have given first aid to these children (5).

In conclusion, the results of this research suggest that there was a significant relationship between the teachers' knowledge and what they had previously heard about epilepsy. Therefore, we can pass this information to the Ministry of Education and encourage them to organize future health education programs for all teachers about epilepsy and how to deal more effectively with epileptic students.

\section{Conflict of interests}

The authors declare that they have no competing interests.

\section{Author's contributions}

S.Kaheni and HR.Reyace have contributed to the designing, writing, revising and approving the final manuscript. S.Kaheni have performed data collection and GhR.Sharifzadeh have done statistic analysis.

\section{Acknowledgement}

We would like to thank the Deputy of Birjand University of Medical Sciences, the Educational Department of Southern Khorasan, the principles, deputies and school health educators. We offer our sincere thanks to the parents and students who helped us in this study.

\section{References}

1. Bekiroglua N, Ozkanb R, Gursesc C, Arpacid B, Dervente A. A study on Awareness and Attitude of Teachers on Epilepsy in Istanbul. Seizure 2004; 13(7): 517-522.

2. Negahi A, Seddiqh-Marvasti F, Zare S, Fallah H, Pourkiani R. Screening of epilepsy among Schoolchildren in Bandar Abbas, Iran. Hormozgan University of Medical Sciences 2011; 15(2): 105-113 (Persian).

3. Masoud S.A, Kochaki E. Surveying Family Attitude of Patients with Epilepsy Hospitalized in Shahid Beheshti Hospital in Kashan. Feyz 2004; 8(1): 79-86 (Persian).

4. Kankirawatana P. Epilepsy Awareness among School Teachers in Thailand. Epilepsia 1999; 40(4): 497-501.

5. Prpic I, Korotaj Z, Cicvaric Vla_sic, Paucic-Kirincic E, Valerjev A, Tomac V. Teachers_opinions about capabilities and behavior of children with epilepsy. Epilepsy Behav 2003 ; 4(2): 142-145.

6. Ghaydaa A, Shehata A, Dalia G. Mahranb. Knowledge, Attitude and Practice Regarding Epilepsy among School Teachers in Assiut city, Egypt. Epilepsy Res 2010; 92 (2-3): 191-200.

7. Moreno Villares JM, Oliveros- Leal L, Simon-Heras R, Mateos- Beato F. Return to the Ketogenic Diet: What Role does It Play in the Treatment of Refractory Seizures of Infancy. Rev Neurol 2001; 32(12): 1115-1119.

8. Kekkonen J, Kokkonen E, Saukkonen A, Pennanen P. Psychosocial Outcome of Young Adults with Epilepsy in Childhood. JNNP 1997; 62(3): 265-268.

9. Rezai A.A, Saiedi S.H. The Study of Age and Sex Frequency of Epilepsy and Its related Factors in Epileptic Patients Referring to Sina and Ghaem Hospital in Hamadan city (1986-1995). Tavanbakhshi 
2000; 2(2): $52-57$ (Persian).

10. Aliker EA, Essien AA. Childhood Epilepsy: Knowledge and Attitude of Primary School Teachers in Port Harcourt, Nigeria Niger. J Med 2005; 14(3): 299-303.

11. Alkhamra H, Tannous A, Hadidi M, Alkhateeb J. Knowledge and Attitudes Towards Epilepsy among School Teachers and Counselors in Jordan. Epilepsy 2012; 24(4): 430-434.

12. Dantas F.G, Cariri G.A, Cariri G.A, Ribeiro Filho A.R. Knowledge and Attitudes Towards Epilepsy among Primary, Secondary and Tertiary Level Teachers. Arq Neuropsiquiatr 2001; 59(3-B): 712-716.

13. Gretchen L, Birbeck, Chomba E, Atadzhanov M, Mbewe E, Haworth A. Zambian Teachers: What do they know about epilepsy and how can we work with them to decrease stigma?. Epilepsy Behav 2006; 9(2): 275-280.
14. Bishop M, Boag EM. Teachers' Knowledge about Epilepsy and Attitudes toward Students with Epilepsy: Results of a National Survey. Epilepsy Behav 2006; 8(2): 397-405.

15. Lee H, Lee S.K, Chung C.K, Yun S.N, Choi-Kwon S. Familiarity, knowledge and Attitudes toward Epilepsy among Teachers in Korean Elementary Schools. Epilepsy Behav 2010; 17(2): 183-87.

16. Kaleyias J, Tzoufi M, Kotsalis C, Papavasiliou A, Diamantopoulos N. Knowledge and Attitude of the Greek Educational Community toward Epilepsy and the Epileptic Students. Epilepsy Behav 2005; 6(2): 179-86.

17. Gharegozli1 K, Abbasi siar F, Kolahil A.S, Bolhari J, Zamani GH, Keyhanidoost Z.T, et al. Public knowledge and attitudes toward Epilepsy in Tehran. TUMJ 2006; 64( 8): 22-30 (Persian). 